Verdú González, D. \& Gómez Carrasco, C.J. (2019). Enseñanza de la historia y concepciones identitarias de los maestros en formación. Diseño y validación del cuestionario CIAMEH. Revista Electrónica Interuniversitaria de Formación del Profesorado, 22(2), 41-65.

DOI: http://dx.doi.org/10.6018/reifop.22.2.370011

\title{
Enseñanza de la historia y concepciones identitarias de los maestros en formación. Diseño y validación del cuestionario $\mathrm{CIAMEH}^{1}$
}

\author{
David Verdú González, Cosme J. Gómez Carrasco
}

Facultad de Educación. Universidad de Murcia

\section{Resumen}

Los cambios sociales recientes han provocado que grupos culturales distintos hayan tenido que vivir juntos, surgiendo conflictos que podrían acarrear problemas muy graves de exclusión social o violencia. Se demanda una educación intercultural que asegure el desarrollo de identidades inclusivas para una convivencia pacífica y democrática. La escuela, los maestros y las lecciones de las ciencias sociales se vuelven particularmente relevantes en la formación identitaria de los futuros ciudadanos, sobre todo las destinadas a la Historia. Por lo tanto, es de suma importancia estudiar la identidad de los futuros docentes y la forma en que ven la enseñanza de la historia, para actuar durante su formación inicial y corregir los prejuicios que pueden ser perjudiciales para su futuro trabajo docente. Este artículo tiene como objetivo la validación de un cuestionario diseñado ad hoc para conocer esa información, a través de la aplicación de una prueba piloto a 23 alumnos de $1 .{ }^{\text {er }}$ curso de Grado en Educación Primaria, el análisis de su fiabilidad y las pruebas de validez de contenido y de constructo. De los datos recogidos se obtuvo que el cuestionario ofrece un índice de validez de contenido IVCG $=0,96$ y un valor de confiabilidad $\alpha=0,914$, datos

\section{Contacto:}

David Verdú González, Email: dvg3@um.es. Facultad de Educación, Despacho 1.26 - Edificio Anexo 30100 - Campus Universitario de Espinardo (Murcia).

Este trabajo se ha elaborado gracias al contrato predoctoral (FPU 14/05354) que recibe el primero de los autores por parte del Ministerio de Educación, Cultura y Deporte.

1"Este trabajo es resultado del proyecto de investigación "La evaluación de las competencias y el desarrollo de capacidades cognitivas sobre historia en Educación Secundaria Obligatoria” (EDU201565621-(3-2-R), subvencionado por el Ministerio de Economía y Competitividad de España y cofinanciado con fondos FEDER de la UE. Asimismo, esta investigación ha recibido financiación del proyecto "Competencias docentes y métodos activos de aprendizaje. Una investigación evaluativa con el profesorado en formación de ciencias sociales" (20638/JLI/18: Fundación Séneca, Agencia de Ciencia y Tecnología de la Región de Murcia)." 
elevados que ofrecen garantías a la hora de aplicar el cuestionario a muestras grandes de alumnado.

\title{
Palabras clave
}

Enseñanza de la historia; creación identitaria; diseño y validación de instrumento de recogida de información; formación inicial del profesorado.

\section{History teaching and identity conceptions of training teachers. Development and validation of the CIAMEH questionnaire}

\begin{abstract}
Recent social changes have led different cultural groups to living together, arising conflicts that could result in very serious problems of social exclusion or violence. An intercultural education that assures the development of inclusive identities for a peaceful and democratic coexistence is demanded. The school, the teachers and the social sciences lessons become particularly relevant in future citizens' identity formation, especially those destined for History. Therefore, it is very important to study the future teachers' identity and the way they conceive the teaching of history, in order to act during their initial training and to correct prejudices that may be detrimental to their future teaching work. This article aims to validate a questionnaire designed ad hoc to know that information, through the application of a pilot test to 23 students in the 1st year of the Degree in Primary Education, the analysis of its reliability and the tests of content validity and construct validity. From the gathered data it was obtained that the questionnaire offers an index of content validity IVCG $=0.96$ and a reliability value $\alpha=0.914$, high data that offer guarantees when applying the questionnaire to large samples of students.
\end{abstract}

\section{Key words}

History education; identity creation; development and validation of an information collection instrument; initial teacher training.

\section{Introducción}

\section{Una sociedad en continuo cambio. La globalización y la crisis mundial}

Los dos últimos decenios de la historia de la humanidad nos presentan una serie de cambios transcendentales. Autores como Bauman (2005) o Castells (2002) propusieron los conceptos de sociedad líquida o sociedad red, respectivamente, para definir los efectos de la globalización de la economía y de las tecnologías de la información. Esos movimientos crearon redes económicas y humanas que promovieron tanto una mayor interdependencia como permeabilidad de las fronteras (Bermejo, 2011). Asimismo, permitieron que cualquier persona, desde casi cualquier lugar, pudiera acceder a la información y que las relaciones económicas a escala planetaria tuvieran repercusiones a nivel político y social. Esos cambios, a su vez, generaron un efecto migratorio, ya que diferentes grupos culturales se movilizaron en busca de mayores y mejores oportunidades. El nuevo contacto entre diferentes culturas que comparten el mismo espacio, tanto físico como virtual, ha propiciado que surjan tanto nuevas relaciones de respeto, comprensión y aprendizaje como de rechazo al que es diferente. Esos nuevos espacios multiculturales, por lo tanto, han 
producido la creación de nuevas relaciones pero, sin embargo, también una crisis identitaria en aquellos que reclaman una identidad asociada al lugar en el que se vive, la cual aclaman como ancestral e inamovible.

Por otro lado, la crisis mundial generó desempleo, programas de austeridad, crisis fronterizas y guerras y, en general, un estado de pesimismo globalizado. Esas guerras, sobre todo las de Medio Oriente, supusieron una crisis de refugiados y el consecuente debate entre los Estados sobre cómo lidiar con una inmigración inesperada (Pausch, 2016). $\mathrm{Si}$ a eso le unimos diferentes ataques terroristas en diferentes partes del mundo, se ha ido generando una atmósfera de miedo y rabia, la cual ha propiciado un rechazo hacia otros grupos culturales y el surgimiento de discursos populistas por parte de movimientos políticos extremistas que intentan ofrecer maneras fáciles de salir de esos 'problemas', bien utilizando de forma partidaria la información o bien manipulándola. Se pueden ver diferentes ejemplos en el contexto europeo y, en el caso concreto de España, se ha podido constatar que los ataques, de distinta tipología, hacia personas musulmanas han crecido hasta llegar a casi 500 casos documentados en 2016 (Bayrakli \& Hafez, 2018).

Pausch (2016) indicó que la educación cívica y para la ciudadanía podría ser una solución a medio-largo plazo para los mencionados problemas por tres motivos: ayuda a tener un conocimiento político de la historia, de las instituciones y de los procedimientos de la democracia; provee de valores democráticos y de comportamiento, y proporciona habilidades para la participación activa en una esfera de comunicación pública.

La enseñanza de la historia y la educación para la ciudadanía y su importancia en la creación de identidades

La historia y su enseñanza, según Gómez y Miralles (2017), tiene una utilidad social y ha de cumplir tanto una labor informadora, en la que el alumnado asimila y comprende diferentes contenidos históricos, como una labor formadora que ha de procurar que el estudiante desarrolle su personalidad y su madurez, a través de trabajar y practicar actitudes de tolerancia, solidaridad y respeto hacia todos los seres humanos y el medio que los rodea.

A menudo, la enseñanza de la historia ha sufrido un uso partidista de manos del poder, el cual solo se ha centrado en la labor informadora, con el objetivo de crear identidades e inculcar valores estrechamente vinculados a las ideologías dominantes y no tanto de desarrollar un conocimiento crítico (Gómez y Miralles, 2017). En contra de ello, se concibe que la enseñanza de la historia y las ciencias sociales ha de preparar al alumnado para que construya sus propios conocimientos, se sitúe en el mundo y esté preparado para intervenir en él de manera activa y democrática (Pagès, 2002).

Las sociedades actuales, para romper con la tendencia uniformadora y excluyente, proponen una educación en la que la tolerancia y el conocimiento del otro, así como la formación de una ciudadanía crítica y participativa, sean las claves del éxito para lograr una convivencia democrática. Ese deseo se ha plasmado a través del concepto de educación cívica o educación para la ciudadanía. Hoy en día, según Sicurello (2016), el concepto de ciudadanía ya no solo se puede circunscribir a la pertenencia a una nación sino que, por razones culturales y éticas, hay que ampliar ese concepto para incluir los derechos humanos universales. Ese trabajo de valores y del pensamiento crítico ayudaría a forjar identidades inclusivas que partan del conocimiento de uno mismo pero también del conocimiento y respeto del otro. En opinión de Rodríguez-Lestegás (2008), uno puede definirse teniendo en cuenta a otros, bien por comparación o bien en relación a ellos, y esa creación de la identidad por oposición a otras personas es muy sencilla, aunque a veces es conflictiva. Por ello, la construcción identitaria está unida al hecho de ponerse en el lugar del otro y 
conocer las diferencias que hay entre él y uno mismo, que es lo que conocemos por alteridad, pudiendo decir que identidad y alteridad se definen y promueven mutuamente.

El pensamiento crítico y las metodologías activas en la enseñanza-aprendizaje de las ciencias sociales. La formación inicial del profesorado

Para hacer frente a ese complejo desafío de formar ciudadanos críticos y participativos, la escuela desempeña un papel primordial, no solo a través de la enseñanza de contenidos y valores democráticos sino dotando de formas de practicar dichos valores en las aulas, para que los alumnos y alumnas puedan aplicarlos también fuera de ellas. Por tanto, los futuros docentes han de tener una preparación inicial que les permita manejar contextos diversos en los que surgen diferentes opiniones y en los que la información puede estar contada de distinta manera.En consecuencia, los estudiantes de Magisterio, en su periplo universitario, deberían recibir, por una parte, formación sobre el fomento del pensamiento crítico y, por otra, sobre metodologías que ayuden a trabajar valores críticos y democráticos.

Por un lado, para trabajar el pensamiento crítico, Marí, Moreno e Hipólito (2016), Santiago (2016) o Moreno-Vera (2018), por nombrar algunos ejemplos, nos muestran cómo las ciencias sociales y la historia son lugares idóneos donde romper con la memorización de fechas, hechos y personajes para desarrollar el pensamiento crítico en la formación ciudadana en un mundo globalizado. Estos autores nos plantean abordar la enseñanza de la historia a través de la narración y los problemas socialmente relevantes y controvertidos, ya que la disparidad de relatos ofrece una mirada crítica sobre un mismo tema, y su tratamiento ayuda a acercar posturas y comprender a los demás.

Por otro lado, atendiendo a lo que nos dicen Gómez, Ortuño y Miralles (2018), la didáctica de las ciencias sociales está intentando cambiar los métodos de enseñanza para romper con el relato lineal, normalmente marcado por un carácter ideológico, y llegar a un proceso de enseñanza aprendizaje que fomente el pensamiento crítico del alumnado a través de la interacción, lo que conllevará la consecución de competencias, habilidades y actitudes. Según estos mismos autores, los docentes han de buscar el fomento del debate, las discusiones y las puestas en común, así como metodologías en las que el alumnado sea el actor protagonista crítico de los acontecimientos y no solo un espectador pasivo y sumiso ante los fenómenos sociales que ocurren a su alrededor.

Investigación en didáctica de las ciencias sociales. Concepciones previas de los futuros docentes como punto de partida de los currículos de didáctica de las ciencias sociales

Las ciencias sociales, según Prats y Fernández (2017), son una serie de disciplinas que estudian el conocimiento de lo social. Aunque ese conocimiento, en palabras de dichos autores, es complejo, diverso, variable e inmaterial, no deja de ser perceptible y, por lo tanto, adquiere la categoría de ciencia, ya que parece generalmente aceptado que el conocimiento científico no está remitido exclusivamente a los resultados sino al conocimiento que se consigue a través de una determinada manera, con un estilo de pensamiento y acción, consiguiendo con ello reproducciones conceptuales de los hechos, fabricando teorías factuales, parciales y factibles. Por lo tanto, la investigación en ciencias sociales ha de seguir los preceptos de cualquier investigación educativa que, según Sabariego y Bisquerra (2014), tiene como características: se desarrolla a través de los métodos de investigación; tiene el objetivo de generar conocimiento sobre educación, resolver problemas y mejorar la práctica y las instituciones educativas; y, por último, está organizada y es sistemática, lo que garantiza la calidad el conocimiento que se genera.

Dentro de la investigación en didáctica de las ciencias sociales podríamos destacar dos tendencias actuales, de entre las recogidas en Miralles, Molina y Ortuño (2011): 
investigaciones sobre la formación inicial de los futuros docentes a través del estudio de sus concepciones sobre diversas cuestiones e investigaciones sobre el uso y enseñanza de la historia en la creación de identidades. Aunque se encuentren diversas investigaciones de cada una de esas tendencias, son escasos los trabajos que tratan de establecer una conexión entre las concepciones identitarias de los futuros docentes y la enseñanza que harían de la historia. El presente estudio forma parte de la investigación Las concepciones de los estudiantes de Grado en Educación Primaria sobre la identidad ante el reto de enseñar Historia, la cual intenta conocer la relación entre la concepción identitaria del alumnado de Grado en Educación Primaria y la enseñanza de la historia que creen que llevarán a cabo en su futura labor profesional.

En el presente trabajo se muestra el proceso de creación ad hoc del cuestionario CIAMEH (Cuestionario sobre concepciones acerca de identidad, alteridad y multiculturalidad para la enseñanza de la historia) y su posterior validación, siguiendo con ello los preceptos del método científico. Por lo tanto, el presente trabajo tiene como objetivo principal el evaluar la validez de un cuestionario que sirva para establecer relaciones entre las concepciones identitarias de los alumnos de Grado en Educación Primaria y la enseñanza de la historia. A su vez, ese objetivo se ha concretado a través de tres objetivos específicos: (1) comprobar la validez de contenido del cuestionario $\mathrm{CIAMEH}$; (2) analizar la fiabilidad del cuestionario CIAMEH; y (3) comprobar la validez de constructo del cuestionario CIAMEH.

\section{Metodología}

\section{Muestra}

Para este estudio participaron 23 alumnos de un grupo de $10^{\circ}$ de Grado de Educación Primaria de la Universidad de Murcia, que sirvieron como muestra para el estudio piloto. La muestra final de la investigación global está formada por 1031 alumnos y alumnas de dicha titulación, pertenecientes a todos los cursos y grupos de dicha titulación en el curso 20162017 , lo que supone un $65,09 \%$ de los alumnos matriculados en ese curso.

Se escogió ese grupo para que formara parte del estudio piloto de forma aleatoria o probabilística, pues ya que se pretendía aplicar el cuestionario a la mayor cantidad de muestra posible, se estableció como piloto a un solo grupo, que fue el primero en acceder a colaborar en la investigación.

\section{Enfoque metodológico}

Para llevar a cabo los objetivos propuestos se planteó una investigación que sigue un diseño ex post-facto que nos permite un análisis descriptivo correlacional con el que identificar, comparar y correlacionar distintos factores. Tiene como finalidad el detectar los sentimientos identitarios del alumnado de Grado en Educación Primaria, futuros maestros y maestras, y su visión tanto de la enseñanza de la historia como de su formación para hacer frente a una educación intercultural. Por lo tanto, el enfoque metodológico adoptado es de tipo cuantitativo, aunque el instrumento contiene una sección con ítems de pregunta abierta que también tuvieron que valorar los jueces en la fase de validación de contenido. Siguiendo este tipo de metodología, la recogida de información y de evidencias es sistemática, rigurosa, objetiva, creíble, fiable y válida (Lukas y Santiago, 2009).

\section{Diseño del cuestionario CIAMEH}

Como se ha comentado previamente, la creación ex profeso del cuestionario CIAMEH debería servir para analizar la concepción identitaria de los futuros docentes en Educación Primaria así como los contenidos y metodologías que emplearían en las clases de historia 
que impartirán en el futuro, con el objetivo de establecer relaciones entre ellos, uniendo con ello las dos tendencias en investigación mencionadas con anterioridad.

El cuestionario CIAMEH se concibió para recoger la información cuantitativa, así como parte de la información cualitativa, puesto que los datos extraídos del cuestionario se complementarán con entrevistas semi-estructuradas y grupos de discusión. El presente artículo se centra en los datos cuantitativos, que son los que permitieron analizar las propiedades psicométricas del instrumento.

Procedimiento

Con el objeto de seguir los parámetros de una investigación científica, el diseño del cuestionario final que se aplicó a los alumnos de Grado de Educación Primaria siguió las siguientes fases (véase Figura 1):

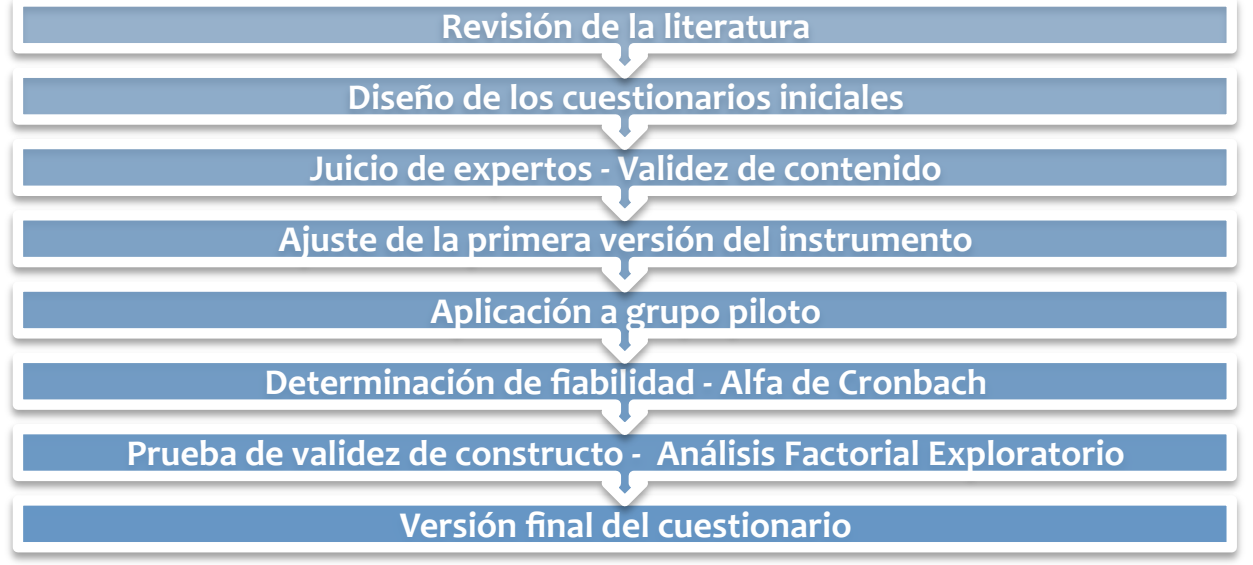

Figura 1. Fases para la creación del cuestionario CIAMEH. Elaboración propia

En una primera fase se revisó, para el diseño del instrumento de recogida de información, la literatura sobre dos temáticas diferentes: trabajos sobre identidad, su definición, la formación identitaria y la construcción de la identidad social en contraste con la alteridad, entre los que destacan los de Prats (2001) y Scandroglio, López y San José (2008). La segunda temática es la que se centra en trabajos sobre instrumentos que preguntan sobre prejuicios, actitudes hacia la multiculturalidad, identidad, tolerancia o sobre estilos de enseñanza, entre los que destacan Alonso y Lobato (2005), Aymerich, Canales y Vivanco (2003), Cheek \& Briggs (2013), Chiang, Díaz, Rivas y Martínez-Geijo (2013), y Rodríguez y Hernández (2011).

De esa revisión surgió el cuestionario $\mathrm{CIAMEH}$, el cual se componía inicialmente de cinco bloques principales y de 60 ítems en total, repartidos de la siguiente manera:

- Bloque 1: variables de identificación (sexo, curso, edad, etc.). 7 ítems.

- Bloque 2: conceptos de identidad y alteridad. Con este bloque se pretendía conocer si los participantes entienden los conceptos de identidad y alteridad y cómo se forja la identidad, para comprobar si saben que ellos influirán en la formación identitaria de sus futuros alumnos. 4 ítems.

- Bloque 3: relación y sentimiento hacia los demás. Por un lado se preguntaba si los alumnos tenían relación con otros grupos culturales y, por otro, su sentimiento hacia otros grupos. 29 ítems. 
- Bloque 4: la enseñanza de la historia según los alumnos de Grado en Primaria. Este bloque pretende conocer tanto los contenidos que los alumnos creen indispensables sobre historia en la Educación Primaria así como la manera de impartirlos. 8 ítems.

- Bloque 5: la interculturalidad en el Grado de Educación Primaria. Este bloque está destinado a conocer la importancia que dan los participantes a la formación para hacer frente a una educación basada en la interculturalidad y, por otro lado, la valoración que hacen de la formación que ellos reciben sobre esa temática según su plan de estudios. 12 ítems, de los que dos de ellos estaban destinados exclusivamente a los alumnos de una mención específica de $4 .^{\circ}$ curso.

No todos los ítems se formularon de igual manera, ya que se recogen ítems con respuestas múltiples, otros con respuestas abiertas para el Bloque 4 y una gran parte de ítems que son respondidos a través de una escala tipo Likert de 4 opciones de respuesta, que oscilaban desde "totalmente en desacuerdo" hasta "totalmente de acuerdo".

\section{Prueba de validez de contenido}

Se envió a cinco jueces expertos (siendo sus especialidades: metodología didáctica, didáctica de las ciencias sociales, historia de la educación, metodología de investigación y educación intercultural) tanto el cuestionario como los objetivos de la investigación y un instrumento para que juzgasen la validez del contenido del cuestionario CIAMEH en su versión inicial. Ese juicio debería servir para comprobar si los ítems estaban bien redactados, si había suficientes para cumplir con los objetivos de la investigación y si eran adecuados para extraer la información buscada. La guía para evaluar se creó también ex profeso siguiendo los trabajos de García-López y Cabero (2011) y Sánchez, Serrano y Alfageme (2011).

La valoración de la validez de los ítems se calculó a través del índice de validez de contenido (IVC). Siguiendo a Vargas y Hernández (2010), el IVC se puede calcular, de forma cuantitativa, siguiendo distintos pasos, ya que podemos extraer:

- Validez de contenido para cada experto: número de ítems con determinada puntuación / número total de ítems.

- Validez de contenido general: suma del IVC calculado para cada uno de los expertos / número de expertos.

- Validez de contenido de cada ítem: número de expertos que concuerdan con determinada puntuación (que indica pertinencia, corrección y relevancia) / número total de expertos.

\section{Aplicación a grupo piloto}

Una vez que se realizaron las correcciones propuestas por los expertos se realizó una prueba piloto a un grupo de $1 .{ }^{\text {er }}$ curso, participando en esa prueba los 23 alumnos que acudieron a clase ese día.

A partir de ese ensayo se pudo estimar el tiempo de aplicación del cuestionario y se realizaron cambios en la redacción de algunos ítems que habían producido confusión en los participantes de esa prueba piloto.

Asimismo, la información obtenida de dicha aplicación sirvió para el cálculo de la fiabilidad del instrumento.

Cálculo de fiabilidad 
La fiabilidad (consistencia interna) del instrumento se calcula a través de la prueba alfa de Cronbach (a), la cual permite estimar la confiabilidad de un instrumento de medida a través de un conjunto de ítems que se espera que midan el mismo constructo o una única dimensión teórica de un constructo latente. La medida de la fiabilidad mediante el alfa de Cronbach asume que los ítems (medidos con una escala tipo Likert o con respuestas dicotómicas) miden un mismo constructo y que están altamente correlacionados entre sí. Por lo tanto, para el cálculo de la fiabilidad del instrumento solo se tuvieron en cuenta los ítems que ofrecían opciones de respuesta mediante escalas tipo Likert, puesto que el resto de ítems (aquellos con respuestas múltiples o respuestas abiertas) ya habían sido validados por los jueces expertos. Esos ítems fueron del 15 al 41 y del 50 al 60.

El valor de alfa de Cronbach oscila de o a 1. Cuanto más cerca se encuentre el valor del alfa a 1 mayor es la consistencia interna de los ítems analizados.Como criterio general, George y Mallery (2003, p. 231) sugieren las recomendaciones siguientes para evaluar los valores de los coeficientes de alfa de Cronbach: $\alpha>.9$ es excelente; $\alpha>.8$ es bueno; $\alpha>.7$ es aceptable; $\alpha>.6$ es cuestionable; $\alpha>.5$ es pobre; $\alpha<.5$ es inaceptable.

Es muy importante que todos los ítems estén puntuados en el mismo sentido y nunca tener ítems en sentido directo e inverso en un mismo análisis de fiabilidad, pues daría valores de alfa de Cronbach bajos e incluso negativos. Para ver si existen valores negativos, como se ha dicho previamente, se debe realizar una correlación bivariada (Rho de Spearman) entre la suma total de los ítems calculada con anterioridad y los propios ítems (Bautista y Mateos, 2012). Se puede controlar que todos los ítems están en el mismo sentido observando la columna de las correlaciones del ítem con la puntuación total (la suma) donde todas tienen que ser correlaciones positivas. Si hay algún coeficiente de correlación negativo, entonces, ese ítem está en un sentido inverso al resto de ítems, por lo que se puede recodificar el ítem para que no aparezca inverso o, si esa recodificación no produce una correlación positiva, eliminar el ítem.

\section{Validez de constructo}

Para comprobar la validez de constructo se pensó en realizar la prueba del análisis factorial exploratorio (AFE). Dicho análisis, según Montoya (2007), consiste en realizar una prueba para descubrir agrupaciones de variables (constructos o dimensiones) en las que las variables de cada grupo están altamente correlacionadas, y los grupos están, en cierta manera, no relacionados, de manera que se logra reducir un número de variables intercorrelacionadas a un número inferior de factores no correlacionados, que permiten explicar la mayor parte de variabilidad de cada una de las variables.

En ocasiones, ese análisis da como resultados modelos indefinidos por diferentes causas. Si atenemos a Wothke (1993), uno de los motivos es la escasez de información proporcionada por los datos. Según ese autor, una muestra baja (mucho más aún si la muestra es menor al número de variables del instrumento) nos dará un resultado indefinido, por lo que el análisis no será válido.

\section{Análisis de los datos}

Ya que, como se explicaba anteriormente, la información iba a ser tratada a través de un análisis estadístico, los datos recogidos por medio de la aplicación del cuestionario que sirvió de instrumento de recogida de la información así como del instrumento de valoración por parte de los jueces fueron codificados y tratados en el paquete estadístico SPSS, versión 20.0., y el programa Microsoft Excel, que sirvió para el cálculo del índice de validez de contenido. 
Asimismo, se analizaron las respuestas y los comentarios de los jueces así como las reacciones de los participantes del grupo piloto para realizar los cambios según dichas respuestas, sin la utilización de ningún software.

Los tratamientos estadísticos realizados se han correspondido a las necesidades de los objetivos propuestos. Consecuentemente, los resultados que se presentan en el bloque siguiente se han obtenido a partir de análisis que buscaban dar respuesta a los objetivos de la investigación.

\section{Resultados}

La descripción de los resultados que se ofrece en este apartado está estructurada de tal manera que se dé respuesta a los objetivos específicos de nuestra investigación, por lo tanto, se presentarán siguiendo dichos objetivos.

\section{Objetivo 1. Comprobar la validez de contenido del cuestionario CIAMEH}

De la información extraída del instrumento que se les facilitó a los expertos para que realizasen su juicio para determinar la validez del contenido del cuestionario se obtuvo un valor del índice de validez de contenido general de IVCG=0,96. Según Vargas y Hernández (2010, p. 99): "El índice de validez de contenido general (IVCG) mayor o igual a 0,80 se considera indicativo de validez de contenido elevada". Por ello, la valoración general tiene un valor que indica que es muy elevada (véase Tabla 1 en Anexo I).

Además de analizar los ítems del cuestionario, se pidió a los expertos que analizaran el cuestionario atendiendo a tres factores: presentación, instrucciones y estructura y diseño, siendo las medias de los ítems de cada bloque 3,24, 3,35 y 3,2188, respectivamente, lo que suponía no realizar cambios sustanciales, puesto que un resultado mayor de 3 se entendía como positivo.

A partir de los comentarios de los expertos se realizaron diferentes cambios en cuanto a redacción se refiere, para que fuesen más claros. Además, hubo otros cambios como fue la inclusión de un ítem para preguntar por el curso al que pertenece el participante; cambiar las escalas tipo Likert de cuatro a cinco opciones de respuesta, incluyendo un valor intermedio "no tengo opinión formada al respecto" y que fuesen todas de un valor negativo a un valor positivo, para poder calcular el índice de correlación de Spearman entre variables.

\section{Objetivo 2. Analizar la fiabilidad del cuestionario CIAMEH}

Para el análisis de la fiabilidad se calcularon tanto las correlaciones entre variables a través del estadístico Rho de Spearman así como el cálculo del alfa de Cronbach. Como se decía en el apartado anterior, este análisis requirió que se recodificasen aquellos ítems que estaban redactados en sentido inverso (véase Tabla 2 ).

Tabla 2.

Clasificación de variables directas e inversas en el cuestionario inicial

\begin{tabular}{ll}
\hline Variables inversas & Ítems 27, 29, 30, 32, 35, 36, 37, 39, 41, 50, 51, 55, 56, 57 y 58 \\
\hline \multirow{2}{*}{ Variables directas } & Ítems 15, 16, 17, 18, 19, 20, 21, 22, 23, 24, 25, 26, 28, 31, 33, 34, 38, 40, 52, \\
& $53,54,59$ y 60
\end{tabular}


El resultado del cálculo de la correlación de variables Rho de Spearman (véase Tabla 3 en Anexo II) y el de fiabilidad a través del alfa de Cronbach (véase Tabla 4) ofrecieron los siguientes resultados:

Tabla 4.

Estadísticos de fiabilidad a través del Alfa de Cronbach

Alfa de Cronbach Alfa de Cronbach basada en los elementos tipificados $\mathrm{N} .^{\circ}$ de elementos ,909 ,917 38

De esos análisis pudimos comprobar que existía una correlación negativa en el ítem 54 (fila sombreada en la Tabla 3 del Anexo II), por lo que se procedió a su eliminación del cuestionario, ya que resultaba redundante con el ítem 53 y cuya eliminación no suponía una rémora en los resultados, según se puede comprobar en la Tabla 5 (véase Anexo III), que muestra la correlación entre los elementos y el total.

A continuación se muestran los cambios realizados en el cuestionario, atendiendo al estudio de la fiabilidad del mismo, y a la correlación entre los ítems y el total:

- Se formuló el ítem número 27 en afirmativo, pasando de "A los alumnos extranjeros generalmente no les gusta estudiar" por "Los alumnos extranjeros son buenos estudiantes".

- Se eliminó el ítem 54, al tener un significado similar al 53 aunque con sentido inverso. Respondiendo al ítem 53 se estaría diciendo si el grado prepara a los futuros maestros.

- El ítem 56 (55 en el cuestionario final) se modificó de la siguiente forma: "Formar a los futuros maestros para que puedan enseñar la perspectiva del otro es imposible, pues el contexto educativo es producto de las propias concepciones y valores" por "Es totalmente posible formar futuros maestros que puedan enseñar la perspectiva del otro aunque el contexto educativo sea producto de las propias concepciones y valores".

- Los ítems 59 y 60 (58 y 59 en la numeración del cuestionario final, respectivamente), se cambiaron para que hubiese una postura reactiva y no neutra, pues el verbo modificar 0 cambiar no nos decía si el encuestado tiene una nueva visión para bien o para mal acerca de los aspectos cuestionados. Por ello, se cambió por la palabra "mejorado", los verbos "cambiado" en el ítem 59 y "modificado" en el ítem 60.

Una vez eliminado el ítem 54 se volvió a calcular el alfa de Cronbach obteniendo un resultado de 0,914 , lo que supone un resultado de "excelente".

\section{Objetivo 3. Comprobar la validez de constructo del cuestionario CIAMEH}

En nuestro caso, teníamos 38 variables y 23 sujetos en el grupo piloto, lo que imposibilitó la realización de una validez de constructo antes de la aplicación del cuestionario definitivo (véase Anexo IV), el cual se diseñó finalmente a través de la validez de contenido, la prueba piloto y la prueba de fiabilidad.

Aun con eso, una vez aplicado el cuestionario definitivo a una población de 1031 participantes, se realizó un AFE para cada conjunto de variables (ítems), para ver el papel que cada ítem juega en cada factor teórico, o bloque, y conocer qué ítems son los que más varianza explican. Esto nos puede permitir ver si algún ítem va muy desencaminado y deberíamos eliminarlo. Ese análisis nos mostró una distribución de los ítems analizados en 8 dimensiones distintas (véase Tabla 6), explicando el $56 \%$ de la varianza total, con un valor en el test Kaiser-Meyer-Olkin (KMO) general de .91 (muy bueno). 
Cuando hicimos el AFE diferenciado para los ítems de los tres distintos bloques analizados (ítems del 15 al 41, ítems del 50 al 55 e ítems del 56 al 59), por corresponderse a información diferente, se obtuvieron los valores del test KMO: 0,92 para el bloque 1, 0,7 para el bloque 2 y 0,6 para del bloque de ítems 3 , que se consideran excelente y bueno, respectivamente, lo que nos indica que está bien planteado aplicar aquí un AFE y que no estamos midiendo diferentes cosas por cada batería de ítems en cada factor.

Tabla 6.

Distribución de los ítems en dimensiones según el AFE

\begin{tabular}{ll}
\hline Dimensión & Ítems \\
\hline 1 & $17,18,19,20,21,22$ y 26. \\
\hline 2 & $27,28,31,33$ y 34. \\
\hline 3 & $53,55,56,57,58$ y 59. \\
\hline 4 & 15 y 16. \\
\hline 5 & $50,51,52$ y 54. \\
\hline 6 & $29,30,32,37,39$ y 41. \\
\hline 7 & 23,24 у 25. \\
\hline 8 & 35 у 36. \\
\hline
\end{tabular}

\section{Conclusiones y limitaciones}

Como resultado de este trabajo se logró obtener un cuestionario que permitía conocer las concepciones identitarias de los alumnos de Grado de Educación Primaria así como su visión de la enseñanza de la historia y de su formación para hacer frente a una educación intercultural.

Se puede concluir que los datos de IVC (0,96 para el IVC general) extraídos del juicio de expertos y los de fiabilidad (Alfa de Cronbach= 0,914) son bastante elevados, lo que da garantías a la hora de aplicar el instrumento a grandes poblaciones. La aplicación al grupo piloto arrojó que los ítems no necesitaban grandes cambios para poder ser entendidos por una población con características similares.

El tener solamente 23 participantes en la prueba piloto hizo que no se pudiera realizar un análisis factorial exploratorio inicialmente, al no disponer de datos suficientes para obtener resultados válidos. Los resultados obtenidos en el AFE, con los 1031 participantes en la investigación, nos indicaron que era pertinente la aplicación de un análisis factorial, y nos especificaron las dimensiones en las que se agrupaban los ítems analizados. La interpretación de dichas dimensiones así como la realización de un análisis factorial confirmatorio nos permitirán comprobar la validez y consistencia interna de las dimensiones obtenidas. Esos análisis ya forman parte de una fase posterior a la del diseño y validación del instrumento CIAMEH.

Si queremos avanzar en el conocimiento en ciencias de la educación, debemos ser rigurosos a la hora de recoger y tratar la información objeto de estudio. Los pasos planteados en este trabajo aseguraron la creación de un cuestionario que debe servir para cumplir con los objetivos propuestos en la investigación, aunque las limitaciones comentadas deben 
tenerse en cuenta en posteriores estudios para poder aplicar con total garantías este instrumento a otras poblaciones.

\section{Referencias}

Alonso Martín, P. y Lobato Soriano, H. (2005). Los prejuicios en una muestra de alumnos de ESO. Cuestiones pedagógicas, 17, 263-276.

Aymerich, J., Canales, M. y Vivanco, M. (2003). Encuesta tolerancia y no discriminación: tercera medición. Chile: Universidad de Chile.

Bauman, Z. (2005). Ética posmoderna. Coyoacán, México: Siglo XXI Editores.

Bautista, V. E. y Mateos, D. (2012). Diseño y validación de un cuestionario de evaluación de la actitud hacia la música clásica del alumnado de Educación Secundaria Obligatoria. Revista Electrónica de Investigación y Docencia (REID), 7, 141-161.

Bayrakli, E. \& Hafez, F. (Eds.) (2018). European Islamophobia Report 2017. Ankara, Turquía: SETA.

Bermejo, D. (2011). Identidad, globalidad y pluralidad en la condición posmoderna. En D. Bermejo (Ed.). La identidad en sociedades plurales (pp. 15-76). Rubí, Barcelona: Anthropos Editorial.

Castells, M. (2002). La era de la información. Economía, sociedad y cultura. Vol. 2. El poder de la identidad. Madrid: Alianza Editorial.

Cheek, J. M. \& Briggs, S. R. (2013). Aspects of Identity Questionnaire (AIQ-IV). Measurement Instrument Database for the Social Science. Recuperado de http://www.midss.org/content/aspects-identity-questionnaire-aiq-iv

Chiang Salgado, M. T., Díaz Larenas, C., Rivas Aguilera, A. y Martínez-Geijo, P. (2013). Validación del cuestionario estilos de enseñanza (CEE). Un instrumento para el docente de educación superior. Revista Estilos de Aprendizaje, 12(11), 30-45.

García-López, E. y Cabero, J. (2011). Diseño y validación de un cuestionario dirigido a describir la evaluación en procesos de educación a distancia. Edutec-e. Revista electrónica de Tecnología Educativa, 35 [versión digital]. Recuperado de http://edutec.rediris.es/Revelec2/Revelec35/pdf/Edutec-e_n35_Garcia_Cabero.pdf

George, D. \& Mallery, P. (2003). SPSS for Windows step by step: A simple guide and reference. 11.0 update (4th ed.). Boston: Allyn \& Bacon.

Gómez Carrasco, C. J. y Miralles Martínez, P. (2017). Los espejos de Clío. Usos y abusos de la Historia en el ámbito escolar. Madrid: Sílex Universidad.

Gómez Carrasco, C. J., Ortuño Molina, J. y Miralles Martínez, P. (2018). Enseñar ciencias sociales con métodos activos de aprendizaje. Reflexiones y propuestas a través de la indagación. Barcelona: Octaedro.

Lukas, J. F. y Santiago, K. (2009). Evaluación Educativa. Madrid: Alianza Editorial.

Marí Ytarte, R. M., Moreno, R., \& Hipólito, N. (2016). Educación y ciudadanía. Propuestas educativas desde la controversia. Foro de Educación, 14(20), 49-69.

Miralles Martínez, P., Molina Puche, S. y Ortuño Molina, J. (2011). La investigación en Didáctica de las Ciencias Sociales. Educatio Siglo XXI, 29(1), 149-174. 
Montoya, O. (2007). Aplicación del análisis factorial a la investigación de mercados. Caso de estudio. Scientia et Technica Año XIII, 35, 281-286.

Moreno-Vera, J. R. (2018). El pensamiento crítico en la enseñanza de la historia a través de temas controvertidos. Actualidades Pedagógicas, (72), 15-28.

Pagès, J. (2002). Aprender a enseñar historia y ciencias sociales: el currículo y la didáctica de las ciencias sociales. Pensamiento Educativo, 30, 255-269.

Pausch, M. (2016). Citizenship Education in Times of Crisis. Foro de Educación, 14(20), 3-9.

Prats, J. (2001). Enseñar Historia: Notas para una didáctica renovadora. Mérida: Junta de Extremadura. Consejería de Educación, Ciencia y Tecnología.

Prats, J., y Fernández, R. (2017) ¿Es posible una explicación objetiva sobre la realidad social? Reflexiones básicas e imprescindibles para investigadores noveles. Didacticae, 1, 97110.

Rodríguez Fernández, A. J. y Hernández Pérez, J. M. (2011). Cuestionario de actitudes hacia la multiculturalidad-CAM.Revista Tamadaba, 14. Recuperado de http://www3.gobiernodecanarias.org/medusa/ecoescuela/tamadaba/files/2011/11/CU ESTIONARIO-DE-ACTITUDES-HACIA-LA-MULTICULTURALIDAD.pdf

Rodríguez-Lestegás, F. (2008). Presentación. En F. Rodríguez-Lestegás (Coord.), Identidad y ciudadanía. Reflexión sobre la construcción de identidades (pp. 7-12). Barcelona: Horsori Editorial.

Sabariego Puig, M. y Bisquerra Alzina, R. (2014). Fundamentos metodológicos de la investigación educativa. En R. Bisquerra Alzina (coord.), Metodología de la investigación educativa (pp. 19-49). Madrid: La Muralla.

Sánchez-Rodríguez, P. A., Serrano, F. J. y Alfageme, M. B. (2011). Evaluación inter-jueces para el proceso de validación de un cuestionario para la investigación. En P. Miralles, S. Molina y A. Santisteban (eds.), La evaluación en la didáctica de las ciencias sociales. Pósteres (pp. 93-102). Murcia: AUPDCS.

Santiago, J. A. (2016). La acción didáctica de las Ciencias Sociales y el desarrollo del pensamiento crítico. Revista Educación y Humanismo, 18(31), 241-256.

Scandroglio, B., López Martínez, J. S. y San José Sebastián, M. C. (2008). La Teoría de la Identidad Social: una síntesis crítica de sus fundamentos, evidencias y controversias. Psicothema, 20(1), 80-89.

Sicurello, R. (2016). Educazione alla cittadinanza: significati, linee di ricerca, finalità e pratiche didattiche. Foro de Educación, 14(20), 71-103.

Vargas Porras, C. y Hernández Molina, L. M. (2010). Validez y confiabilidad del cuestionario "Prácticas de cuidado que realizan consigo mismas las mujeres en el posparto". Avances en Enfermería, XXVIII(1), 96-106.

Wothke, W. (1993). Non positive definite matrices in structural modeling. In K. A. Bollen \& J. S. Long (Eds.), Testing Structural Equation Models (pp. 256-293). Newbury Park NJ: Sage. 


\section{Anexos}

Anexo I. Cálculo del IVC por jueces expertos

Tabla 1.

Cálculos de IVC por experto, general y por ítem

\begin{tabular}{|c|c|c|c|c|c|c|}
\hline ÍTEM & Juez 1 & Juez 2 & Juez 3 & Juez 4 & Juez 5 & IVC por ítem \\
\hline 1 & 1 & 1 & 1 & 1 & 1 & 1,000 \\
\hline 2 & 1 & 1 & 1 & 3 & 1 & 1,000 \\
\hline 3 & 1 & 1 & 1 & 1 & 1 & 1,000 \\
\hline 4 & 1 & 2 & 1 & 3 & 1 & 0,800 \\
\hline 5 & 1 & 3 & 1 & 3 & 1 & 1,000 \\
\hline 6 & 1 & 1 & 3 & 3 & 1 & 1,000 \\
\hline 6.1 & 1 & 1 & 1 & 1 & 1 & 1,000 \\
\hline 7 & 1 & 4 & 1 & 3 & 1 & 0,800 \\
\hline 8 & 1 & 3 & 1 & 3 & 1 & 1,000 \\
\hline 9 & 1 & 1 & 1 & 1 & 2 & 0,800 \\
\hline 10 & 1 & 1 & 1 & 1 & 1 & 1,000 \\
\hline 11 & 1 & 3 & 1 & 3 & 1 & 1,000 \\
\hline 12 & 1 & 1 & 3 & 1 & 1 & 1,000 \\
\hline 12.1 & 1 & 3 & 1 & 3 & 1 & 1,000 \\
\hline 12.2 & 1 & 1 & 1 & 3 & 1 & 1,000 \\
\hline 13 & 1 & 1 & 1 & 3 & 1 & 1,000 \\
\hline 14 & 1 & 1 & 1 & 3 & 1 & 1,000 \\
\hline 15 & 1 & 1 & 1 & 3 & 1 & 1,000 \\
\hline 16 & 1 & 1 & 1 & 3 & 1 & 1,000 \\
\hline 17 & 1 & 1 & 1 & 3 & 1 & 1,000 \\
\hline 18 & 1 & 1 & 1 & 3 & 1 & 1,000 \\
\hline 19 & 1 & 1 & 1 & 3 & 1 & 1,000 \\
\hline 20 & 1 & 1 & 1 & 3 & 1 & 1,000 \\
\hline 21 & 1 & 1 & 1 & 3 & 1 & 1,000 \\
\hline 22 & 1 & 1 & 1 & 3 & 1 & 1,000 \\
\hline 23 & 1 & 1 & 1 & 3 & 1 & 1,000 \\
\hline 24 & 1 & 3 & 1 & 3 & 1 & 1,000 \\
\hline 25 & 1 & 3 & 1 & 3 & 1 & 1,000 \\
\hline 26 & 1 & 1 & 1 & 3 & 1 & 1,000 \\
\hline 27 & 1 & 3 & 1 & 3 & 1 & 1,000 \\
\hline 28 & 1 & 3 & 1 & 3 & 1 & 1,000 \\
\hline 29 & 1 & 3 & 1 & 3 & 1 & 1,000 \\
\hline 30 & 1 & 3 & 1 & 3 & 1 & 1,000 \\
\hline 31 & 1 & 3 & 1 & 3 & 1 & 1,000 \\
\hline 32 & 1 & 3 & 1 & 3 & 1 & 1,000 \\
\hline 33 & 1 & 3 & 1 & 3 & 1 & 1,000 \\
\hline 34 & 1 & 3 & 1 & 3 & 1 & 1,000 \\
\hline
\end{tabular}



CIAMEH

\begin{tabular}{|c|c|c|c|c|c|c|}
\hline ÍTEM & Juez 1 & Juez 2 & Juez 3 & Juez 4 & Juez 5 & IVC por ítem \\
\hline 35 & 1 & 1 & 1 & 3 & 1 & 1,000 \\
\hline 36 & 1 & 1 & 1 & 3 & 1 & 1,000 \\
\hline 37 & 1 & 3 & 1 & 3 & 1 & 1,000 \\
\hline 38 & 1 & 1 & 1 & 3 & 1 & 1,000 \\
\hline 39 & 1 & 1 & 1 & 3 & 1 & 1,000 \\
\hline 40 & 1 & 3 & 1 & 3 & 1 & 1,000 \\
\hline 41 & 1 & 3 & 1 & 3 & 2 & 0,800 \\
\hline 42 & 1 & 1 & 3 & 3 & 1 & 1,000 \\
\hline 43 & 1 & 1 & 3 & 3 & 1 & 1,000 \\
\hline 44 & 1 & 3 & 3 & 3 & 1 & 1,000 \\
\hline 45 & 1 & 3 & 3 & 3 & 1 & 1,000 \\
\hline 46 & 1 & 1 & 3 & 3 & 1 & 1,000 \\
\hline 47 & 1 & 1 & 3 & 3 & 1 & 1,000 \\
\hline 48 & 1 & 1 & 3 & 3 & 2 & 0,800 \\
\hline 49 & 1 & 1 & 1 & 3 & 1 & 1,000 \\
\hline 50 & 1 & 1 & 3 & 3 & 1 & 1,000 \\
\hline 51 & 1 & 1 & 1 & 3 & 1 & 1,000 \\
\hline 52 & 1 & 3 & 2 & 3 & 1 & 0,800 \\
\hline 53 & 1 & 1 & 2 & 3 & 1 & 0,800 \\
\hline 54 & 1 & 3 & 2 & 3 & 1 & 0,800 \\
\hline 55 & 1 & 1 & 2 & 3 & 1 & 0,800 \\
\hline 56 & 1 & 3 & 1 & 1 & 1 & 1,000 \\
\hline 57 & 1 & 1 & 2 & 1 & 1 & 0,800 \\
\hline 58 & 1 & 1 & 2 & 3 & 1 & 0,800 \\
\hline 59 & 1 & 1 & 2 & 3 & 1 & 0,800 \\
\hline 60 & 1 & 1 & 2 & 3 & 1 & 0,800 \\
\hline IVC por experto & 1,00 & 0,968 & 0,873 & 1,000 & 0,952 & \\
\hline
\end{tabular}




\section{Anexo II. Cálculo de correlaciones entre variables}

Tabla 3.

Correlaciones de variables a través del cálculo Rho de Spearman

suma

Rho de Los murcianos son personas con quienes no me importaría Coeficiente de ,309 Spearman convivir y/o trabajar correlación

Los andaluces son personas con quienes no me importaría Coeficiente convivir y/o trabajar correlación

Los catalanes son personas con quienes no me importaría convivir Coeficiente y/o trabajar correlación

Los vascos son personas con quienes no me importaría convivir Coeficiente y/o trabajar correlación

Los franceses son personas con quienes no me importaría convivir Coeficiente y/o trabajar correlación

Los alemanes son personas con quienes no me importaría convivir Coeficiente y/o trabajar correlación

Los británicos son personas con quienes no me importaría Coeficiente convivir y/o trabajar correlación

Los rumanos son personas con quienes no me importaría convivir Coeficiente y/o trabajar correlación

Los magrebíes son personas con quienes no me importaría Coeficiente convivir y/o trabajar correlación

Los sirios son personas con quienes no me importaría convivir y/o Coeficiente trabajar correlación

Los subsaharianos son personas con quienes no me importaría Coeficiente convivir y/o trabajar correlación

Los hispanoamericanos son personas con quienes no me Coeficiente importaría convivir y/o trabajar correlación

A los alumnos extranjeros generalmente no les gusta estudiar Coeficiente correlación

Los inmigrantes enriquecen nuestra sociedad culturalmente

Coeficiente correlación

Las personas de otras culturas fomentan la conflictividad, tanto Coeficiente en las aulas como en ambientes laborales correlación

\begin{tabular}{|c|c|}
\hline Los extranjeros no conocen las normas, son incívicos & $\begin{array}{l}\text { Coeficiente de }, 651^{* *} \\
\text { correlación }\end{array}$ \\
\hline $\begin{array}{l}\text { Las personas venidas de fuera de España son un elemento } \\
\text { positivo en el crecimiento económico }\end{array}$ & $\begin{array}{l}\text { Coeficiente de ,340 } \\
\text { correlación }\end{array}$ \\
\hline $\begin{array}{l}\text { Los inmigrantes abusan de los servicios sanitarios y llegan a } \\
\text { colapsarlos }\end{array}$ & $\begin{array}{l}\text { Coeficiente de }, 676^{* *} \\
\text { correlación }\end{array}$ \\
\hline Podemos aprender mucho de los inmigrantes & $\begin{array}{l}\text { Coeficiente de }, 627^{* *} \\
\text { correlación }\end{array}$ \\
\hline $\begin{array}{l}\text { Hay que dar facilidades a los extranjeros para crear grupos con los } \\
\text { que defender sus derechos }\end{array}$ & $\begin{array}{l}\text { Coeficiente } \\
\text { correlación }\end{array}$ \\
\hline $\begin{array}{l}\text { Debería haber zonas de viviendas donde los inmigrantes se } \\
\text { relacionen entre ellos }\end{array}$ & $\begin{array}{l}\text { Coeficiente } \\
\text { correlación }\end{array}$ \\
\hline
\end{tabular}


Prevendría a un amigo si se quisiera casar con alguien de otra Coeficiente cultura correlación

Los inmigrantes, normalmente, no quieren integrarse y ellos Coeficiente mismos crean guetos correlación

No tendría problema en tener una pareja de otra cultura o Coeficiente procedencia correlación

Los alumnos inmigrantes reducen el nivel educativo de los no Coeficiente inmigrantes correlación

Los alumnos de otras culturas benefician una mejor educación en Coeficiente valores correlación

Los extranjeros tienen que adaptarse y adoptar nuestra cultura, Coeficiente dejando la suya de lado correlación

Ya que el alumnado es mayoritariamente homogéneo, abordar la Coeficiente interculturalidad en la formación del profesorado es innecesario correlación

Es suficiente la existencia de charlas y seminarios, e innecesario Coeficiente que haya contenidos específicos en la carrera sobre estos temas correlación Son necesarias varias asignaturas dentro de la titulación Coeficiente relacionadas con la interculturalidad para formar adecuadamente correlación al profesorado

El plan de estudios del grado incluye asignaturas comunes y Coeficiente contenidos suficientes para que todos los graduados, hagan la correlación mención que hagan, sean capaz de llevar a cabo esa enseñanza en valores y competencias cívicas, democráticas e interculturales

El plan de estudios no asegura que los futuros maestros sean Coeficiente de -,008 capaces de lograr que sus alumnos aprendan y desarrollen las correlación competencias necesarias para formar parte de una sociedad basada en el respeto y en valores democráticos

Los maestros y maestras deberían estudiar más contenidos de las Coeficiente asignaturas específicas y no detenerse en aspectos transversales correlación como los valores y la identidad, ya que eso es algo que los alumnos y alumnas deberían aprender en casa

Formar a los futuros maestros para que puedan enseñar la Coeficiente perspectiva del otro es imposible, pues el contexto educativo es correlación producto de las propias concepciones y valores

He recibido formación suficiente para hacer frente a una Coeficiente educación cargada de valores cívicos, democráticos e identitarios correlación en las asignaturas comunes del Grado

Independientemente de los contenidos estudiados, me siento Coeficiente incapaz de hacer frente a un aula multicultural en mi futuro correlación docente próximo

Las asignaturas comunes del grado han cambiado mi visión hacia Coeficiente otras culturas correlación

Las asignaturas comunes del grado han modificado mi visión hacia Coeficiente de ,038 la necesidad de una educación intercultural correlación de, $786^{* *}$

de ,303

de, $688^{* *}$

de, $580^{*}$

de, $617^{*}$

de, $605^{*}$

de, 405

de, $589^{*}$

de ,240

de ,458 


\section{Anexo III. Tabla estadísticos correlaciones suma total- elemento}

Tabla 5.

Estadísticos total-elemento

\begin{tabular}{|c|c|c|c|c|}
\hline & $\begin{array}{l}\text { Media de la } \\
\text { escala si se } \\
\text { elimina el } \\
\text { elemento }\end{array}$ & $\begin{array}{c}\text { Varianza de } \\
\text { la escala si se } \\
\text { elimina el } \\
\text { elemento }\end{array}$ & $\begin{array}{l}\text { Correlación } \\
\text { elemento- } \\
\text { total } \\
\text { corregida }\end{array}$ & $\begin{array}{c}\text { Alfa de } \\
\text { Cronbach si } \\
\text { se elimina el } \\
\text { elemento }\end{array}$ \\
\hline $\begin{array}{l}\text { Los murcianos son personas con quienes no } \\
\text { me importaría convivir y/o trabajar }\end{array}$ & 143,81 & 401,363 & ,370 & ,910 \\
\hline $\begin{array}{l}\text { Los andaluces son personas con quienes no } \\
\text { me importaría convivir y/o trabajar }\end{array}$ & 143,94 & 393,396 &, 530 &, 908 \\
\hline $\begin{array}{l}\text { Los catalanes son personas con quienes no } \\
\text { me importaría convivir y/o trabajar }\end{array}$ & 144,81 & 370,696 &, 565 & ,906 \\
\hline $\begin{array}{l}\text { Los vascos son personas con quienes no me } \\
\text { importaría convivir y/o trabajar }\end{array}$ & 144,56 & 378,529 & ,626 & ,906 \\
\hline $\begin{array}{l}\text { Los franceses son personas con quienes no } \\
\text { me importaría convivir y/o trabajar }\end{array}$ & 144,56 & 374,129 &, 526 & ,907 \\
\hline $\begin{array}{l}\text { Los alemanes son personas con quienes no } \\
\text { me importaría convivir y/o trabajar }\end{array}$ & 144,19 & 390,696 & ,484 & ,908 \\
\hline $\begin{array}{l}\text { Los británicos son personas con quienes no } \\
\text { me importaría convivir y/o trabajar }\end{array}$ & 144,13 & 388,517 &, 568 & ,907 \\
\hline $\begin{array}{l}\text { Los rumanos son personas con quienes no } \\
\text { me importaría convivir y/o trabajar }\end{array}$ & 144,50 & 384,400 &, 544 & ,907 \\
\hline $\begin{array}{l}\text { Los magrebíes son personas con quienes no } \\
\text { me importaría convivir y/o trabajar }\end{array}$ & 144,44 & 373,329 & ,845 & ,904 \\
\hline $\begin{array}{l}\text { Los sirios son personas con quienes no me } \\
\text { importaría convivir y/o trabajar }\end{array}$ & 144,75 & 369,933 &, 762 & ,904 \\
\hline $\begin{array}{l}\text { Los subsaharianos son personas con quienes } \\
\text { no me importaría convivir y/o trabajar }\end{array}$ & 144,44 & 372,129 & ,817 & ,904 \\
\hline $\begin{array}{l}\text { Los hispanoamericanos son personas con } \\
\text { quienes no me importaría convivir y/o } \\
\text { trabajar }\end{array}$ & 144,19 & 379,763 & ,779 & ,905 \\
\hline $\begin{array}{l}\text { A los alumnos extranjeros generalmente no } \\
\text { les gusta estudiar }\end{array}$ & 145,00 & 403,333 & ,003 & ,915 \\
\hline $\begin{array}{l}\text { Los inmigrantes enriquecen nuestra } \\
\text { sociedad culturalmente }\end{array}$ & 144,81 & 381,363 & ,691 & ,906 \\
\hline $\begin{array}{l}\text { Las personas de otras culturas fomentan la } \\
\text { conflictividad, tanto en las aulas como en } \\
\text { ambientes laborales }\end{array}$ & 145,06 & 370,063 & ,731 & ,904 \\
\hline $\begin{array}{l}\text { Los extranjeros no conocen las normas, son } \\
\text { incívicos }\end{array}$ & 144,50 & 383,733 & ,616 & ,907 \\
\hline $\begin{array}{l}\text { Las personas venidas de fuera de España } \\
\text { son un elemento positivo en el crecimiento } \\
\text { económico }\end{array}$ & 145,25 & 395,933 & ,160 & ,912 \\
\hline $\begin{array}{l}\text { Los inmigrantes abusan de los servicios } \\
\text { sanitarios y llegan a colapsarlos }\end{array}$ & 145,31 & 366,363 & ,634 & ,905 \\
\hline $\begin{array}{l}\text { Podemos aprender mucho de los } \\
\text { inmigrantes }\end{array}$ & 144,88 & 382,383 &, 541 & ,907 \\
\hline
\end{tabular}




\begin{tabular}{|c|c|c|c|c|}
\hline $\begin{array}{l}\text { Hay que dar facilidades a los extranjeros } \\
\text { para crear grupos con los que defender sus } \\
\text { derechos }\end{array}$ & 145,13 & 378,783 &, 560 & 907 \\
\hline $\begin{array}{l}\text { Debería haber zonas de viviendas donde los } \\
\text { inmigrantes se relacionen entre ellos }\end{array}$ & 145,00 & 383,200 &, 421 & 909 \\
\hline $\begin{array}{l}\text { Prevendría a un amigo si se quisiera casar } \\
\text { con alguien de otra cultura }\end{array}$ & 144,44 & 370,796 & ,754 & ,904 \\
\hline $\begin{array}{l}\text { Los inmigrantes, normalmente, no quieren } \\
\text { integrarse y ellos mismos crean guetos }\end{array}$ & 145,13 & 390,250 &, 342 & ,909 \\
\hline $\begin{array}{l}\text { No tendría problema en tener una pareja de } \\
\text { otra cultura o procedencia }\end{array}$ & 145,44 & 365,463 & 635 & ,905 \\
\hline $\begin{array}{l}\text { Los alumnos inmigrantes reducen el nivel } \\
\text { educativo de los no inmigrantes }\end{array}$ & 145,06 & 381,396 & ,433 & ,908 \\
\hline $\begin{array}{l}\text { Los alumnos de otras culturas benefician } \\
\text { una mejor educación en valores }\end{array}$ & 145,19 & 384,163 & ,435 & 908 \\
\hline $\begin{array}{l}\text { Los extranjeros tienen que adaptarse y } \\
\text { adoptar nuestra cultura, dejando la suya de } \\
\text { lado }\end{array}$ & 144,94 & 376,463 & ,638 & ,906 \\
\hline $\begin{array}{l}\text { Ya que el alumnado es mayoritariamente } \\
\text { homogéneo, abordar la interculturalidad en } \\
\text { la formación del profesorado es innecesario }\end{array}$ & 144,50 & 398,267 & ,135 & ,912 \\
\hline $\begin{array}{l}\text { Es suficiente la existencia de charlas y } \\
\text { seminarios, e innecesario que haya } \\
\text { contenidos específicos en la carrera sobre } \\
\text { estos temas }\end{array}$ & 144,56 & 391,196 &, 364 & ,909 \\
\hline $\begin{array}{l}\text { Son necesarias varias asignaturas dentro de } \\
\text { la titulación relacionadas con la } \\
\text { interculturalidad para formar } \\
\text { adecuadamente al profesorado } \\
\end{array}$ & 144,94 & 396,596 & 236 & ,910 \\
\hline $\begin{array}{l}\text { El plan de estudios del grado incluye } \\
\text { asignaturas comunes y contenidos } \\
\text { suficientes para que todos los graduados, } \\
\text { hagan la mención que hagan, sean capaz de } \\
\text { llevar a cabo esa enseñanza en valores y } \\
\text { competencias cívicas, democráticas e } \\
\text { interculturales }\end{array}$ & 144,88 & 393,183 &, 318 & ,910 \\
\hline $\begin{array}{l}\text { El plan de estudios no asegura que los } \\
\text { futuros maestros sean capaces de lograr } \\
\text { que sus alumnos aprendan y desarrollen las } \\
\text { competencias necesarias para formar parte } \\
\text { de una sociedad basada en el respeto y en } \\
\text { valores democráticos }\end{array}$ & 145,81 & 402,029 & ,041 & ,913 \\
\hline $\begin{array}{l}\text { Los maestros y maestras deberían estudiar } \\
\text { más contenidos de las asignaturas } \\
\text { específicas y no detenerse en aspectos } \\
\text { transversales como los valores y la } \\
\text { identidad, ya que eso es algo que los } \\
\text { alumnos y alumnas deberían aprender en } \\
\text { casa }\end{array}$ & 144,44 & 390,396 & ,282 & ,910 \\
\hline
\end{tabular}




\begin{tabular}{|c|c|c|c|c|}
\hline $\begin{array}{l}\text { Formar a los futuros maestros para que } \\
\text { puedan enseñar la perspectiva del otro es } \\
\text { imposible, pues el contexto educativo es } \\
\text { producto de las propias concepciones y } \\
\text { valores }\end{array}$ & 144,94 & 400,863 & ,094 & ,912 \\
\hline $\begin{array}{l}\text { He recibido formación suficiente para hacer } \\
\text { frente a una educación cargada de valores } \\
\text { cívicos, democráticos e identitarios en las } \\
\text { asignaturas comunes del Grado }\end{array}$ & 145,88 & 397,583 & ,136 & ,912 \\
\hline $\begin{array}{l}\text { Independientemente de los contenidos } \\
\text { estudiados, me siento incapaz de hacer } \\
\text { frente a un aula multicultural en mi futuro } \\
\text { docente próximo }\end{array}$ & 145,00 & 384,000 &, 368 & ,909 \\
\hline $\begin{array}{l}\text { Las asignaturas comunes del grado han } \\
\text { cambiado mi visión hacia otras culturas }\end{array}$ & 146,00 & 384,267 &, 362 & ,910 \\
\hline $\begin{array}{l}\text { Las asignaturas comunes del grado han } \\
\text { modificado mi visión hacia la necesidad de } \\
\text { una educación intercultural }\end{array}$ & 145,38 & 401,850 &, 038 & ,914 \\
\hline
\end{tabular}




\section{Anexo IV. Cuestionario CIAMEH final validado \\ CUESTIONARIO SOBRE CONCEPCIONES ACERCA DE IDENTIDAD, ALTERIDAD Y MULTICULTURALIDAD PARA LA ENSEÑANZA DE LA HISTORIA (CIAMEH)}

El presente cuestionario forma parte de una investigación llevada a cabo desde el Departamento de Didáctica de las Ciencias Matemáticas y Sociales de la Facultad de Educación de la Universidad de Murcia, y formará parte de la tesis doctoral de David Verdú González.

La finalidad de la investigación es identificar los sentimientos, opiniones y actitudes del alumnado del Grado en Educación Primaria hacia la educación en valores y su inclusión en los programas docentes de su titulación, así como la relación de la formación identitaria con la enseñanza-aprendizaje de contenidos históricos.

Esa relación es uno de los principales temas de estudio de la investigación en didáctica de las ciencias sociales en la actualidad.

Necesitamos de su colaboración, como alumno o alumna de dicho grado. Estamos realmente interesados en lo que tiene que decir. Es un ejercicio voluntario y totalmente anónimo, no se trata de un examen ni se obtendrá calificación alguna con él. Aún así, se pide la mayor colaboración posible. Por ello, no se buscan respuestas correctas, sino la mayor sinceridad que posibilite extraer información lo más veraz posible.

Asimismo, se solicita colaboración para una segunda fase de la investigación, a través de la participación en una entrevista individual y un grupo de discusión sobre los temas abordados. Dicha participación llevará consigo un obsequio. Si desea participar, déjenos un dato de contacto (teléfono o email), el cual será utilizado solamente para este cometido y será mantenido a través de la más estricta confidencialidad y anonimato.

Datos de contacto:

Para cada pregunta de este cuestionario tiene que escoger solo una respuesta.

Haga un círculo para señalarla. Tómese su tiempo para responder a cada una.

Si necesita cualquier aclaración, por sencilla que parezca, no dude en consultarnos.

Muchas gracias.

\section{BLOQUE 1. IDENTIFICACIÓN}

1. Curso:
a) Primero.
b) Segundo.
c) Tercero.
d) Cuarto.
1.1. Si está cursando $4 .^{\circ}$, ¿qué mención hace?:
a) Educación musical.
b) Educación física.
c) Lengua extranjera francés.
d) Lengua extranjera inglés.
e) Necesidades específicas de apoyo educativo.
f) Ed. Intercultural y Dificultades de aprendizaje.
g) Apoyo educativo en dificultades de A y L.
h) Recursos educativos para escuela y TL.

2. Sexo:
a) Mujer.
b) Hombre.

3. Edad:
a) Hasta 20 años.
b) Entre 21 y 25 años.
c) Entre 26 y 30 años.
d) Entre 31 y 35 años.
e) Más de 35 años.

3. Procedencia:
a) De la Región de Murcia.
b) De otra zona de España.
c) No soy español, pero sí europeo.
d) No soy europeo. Soy de

5. Lengua materna:
a) Español o castellano.
b) Otra, ¿cuál?
6. Acceso al Grado en Educación Primaria:
a) EGB, BUP y COU + Selectividad.
b) ESO y Bachillerato + Selectividad.
c) Formación Profesional.
d) Acceso a mayores (25, 40 o 45 años).
e) Titulados universitarios.

6.1. En caso de haber hecho Bachillerato, ¿cuál hizo?:

a) Humanidades.

b) Ciencias de la Naturaleza y la Salud.

c) Tecnología.

d) Ciencias Sociales.

e) Artes.

f) Otro, ¿cuál?

7. ¿Tiene otra carrera?:

a) No.

b) Sí, ¿cuál? 


\section{BLOQUE 2. CONCEPTOS DE IDENTIDAD y ALTERIDAD}

8. Según su punto de vista, ¿qué definición de identidad es la más correcta?

a) Conjunto de rasgos de un individuo o colectividad, que vienen definidos por la propia naturaleza del individuo o comunidad, sin influencias, y que los diferencian de los demás.

b) Conjunto de rasgos que caracterizan a un individuo o comunidad y que se forman a lo largo del tiempo, influenciados por la convivencia con otras personas o grupos por lo que, más que por oposición, la identidad nos sirve para identificarnos con las otras personas.

c) El concepto de identidad es múltiple y dinámico, lo que nos hace entender que no existe una única identidad individual sino varias que pueden entrar en contradicción entre ellas y, por lo tanto, elegimos nuestra identidad en función del interés particular y en un momento preciso.

d) Cada persona es diferente y sus rasgos son distintos a los de los demás y, aunque un individuo pertenezca a una comunidad, no tiene rasgos comunes al resto de miembros de esa comunidad, pues son esos rasgos propios los definen su identidad.

e) No lo sé.

9. ¿Qué factores cree que forjan la identidad?

a) La personalidad de cada uno y la influencia de la familia.

b) La educación, los entornos sociales y culturales en los que nos movemos, y los medios de comunicación ayudan a definirnos y nos marcan cómo hemos de ser para ser reconocidos por el grupo.

c) La suma de todo lo anterior.

d) Solamente la propia personalidad y los propios pensamientos y sentimientos.

e) No lo sé.

10. ¿Sabe lo que significa alteridad?

a) Acción y efecto de ponerse nervioso y/o alterarse.

b) Intentar ser otra persona, dejando de ser uno mismo.

c) Ponerse en el lugar de otra persona e intentar ver las cosas desde su punto de vista.

d) No lo sé.

11. El conocimiento del otro se refiere al hecho de ser conocedor de la forma de pensar y las características culturales de personas ajenas a nuestra cultura. ¿Cree que dicho conocimiento facilita la convivencia multicultural?
a) Nunca.
b) Solo en contadas ocasiones.
c) A veces.
d) Casi siempre.
e) Siempre.

\section{BLOQUE 3. RELACIÓN Y SENTIMIENTO HACIA LOS DEMÁS}

12. ¿Con cuál de las opciones se siente más identificado? Me siento...
a) Más de mi localidad.
b) Más de mi provincia (o Comunidad Autónoma).
c) Más de mi país.
d) Más europeo (o de otro continente).
e) Ciudadano del mundo.
f) Tan de mi localidad como de mi provincia.
g) Tan de mi provincia como de mi país.
h) De mi provincia, de mi país y
i) Ni de mi provincia, ni de mi país, yo me siento

13. ¿Tiene relación con personas de otras nacionalidades y/o culturas?
a) No.
b) Sí 
13.1. En caso de respuesta afirmativa en la cuestión anterior, ¿qué tipo de relación tiene?

(Si tienes relación con más de una persona, piensa en la que más tratas).
a) Académica.
b) Laboral.
c) De vecindad.
d) A través de actividades (como programas de voluntariado o de acogida).
e) A través de Internet.
f) Amistad de cualquier tipo (familiar, solo conocidos, amistad cercana).
g) Otra, ¿de qué tipo?

13.2. ¿Con qué frecuencia tiene relación con esas personas?
a) Con menos frecuencia que una vez al año.
b) Una vez al año.
c) Mensualmente.
d) Semanalmente.
e) A diario.

14. ¿Siente interés por conocer las culturas de los demás?

a) No, no estoy interesado en conocer a personas de otros países ni otras culturas.

b) Aunque no me importa conocer gente de otros países o culturas, no me interesa su cultura.

c) Sí, me gustaría conocer otras culturas, pero no estoy interesado en conocer a sus gentes.

d) Sí, me gustaría conocer distintas culturas y personas.

Elija solo aquella afirmación que más se ajuste a lo que usted piensa para cada grupo de personas, utilizando la frase siguiente con cada uno de ellos para responder, y siendo las opciones de respuesta: a) Totalmente en desacuerdo, b) Parcialmente en desacuerdo, c) No tengo una opinión formada al respecto, d) Parcialmente de acuerdo y e) Totalmente de acuerdo.

"Los son personas con quienes no me importaría convivir y/o trabajar"

$\begin{array}{llllll}\text { 15. Murcianos: } & \text { a) } & \text { b) } & \text { c) } & \text { d) } & \text { e) } \\ \text { 16. Andaluces: } & \text { a) } & \text { b) } & \text { c) } & \text { d) } & \text { e) } \\ \text { 17. Catalanes: } & \text { a) } & \text { b) } & \text { c) } & \text { d) } & \text { e) } \\ \text { 18. Vascos: } & \text { a) } & \text { b) } & \text { c) } & \text { d) } & \text { e) } \\ \text { 19. Franceses: } & \text { a) } & \text { b) } & \text { c) } & \text { d) } & \text { e) } \\ \text { 20. Alemanes: } & \text { a) } & \text { b) } & \text { c) } & \text { d) } & \text { e) } \\ \text { 21. Británicos: } & \text { a) } & \text { b) } & \text { c) } & \text { d) } & \text { e) } \\ \text { 22. Rumanos: } & \text { a) } & \text { b) } & \text { c) } & \text { d) } & \text { e) } \\ \text { 23. Magrebíes: } & \text { a) } & \text { b) } & \text { c) } & \text { d) } & \text { e) } \\ \text { 24. Sirios: } & \text { a) } & \text { b) } & \text { c) } & \text { d) } & \text { e) } \\ \text { 25. Subsaharianos: } & \text { a) } & \text { b) } & \text { c) } & \text { d) } & \text { e) } \\ \text { 26. Hispanoamericanos: } & \text { a) } & \text { b) } & \text { c) } & \text { d) } & \text { e) }\end{array}$

A continuación se ofrecen distintas afirmaciones referidas a personas procedentes de otros lugares y/o culturas. Marque la respuesta, en cada fila, que mejor se ajuste a su opinión, siendo a) Totalmente en desacuerdo, b) Parcialmente en desacuerdo, c) No tengo una opinión formada al respecto, d) Parcialmente de acuerdo y e) Totalmente de acuerdo.

27. "Los alumnos extranjeros son buenos estudiantes".

a) b) c) d) e)

28. "Los inmigrantes enriquecen nuestra sociedad culturalmente".

a) b) c) d) e)

29. "Las personas de otras culturas fomentan la conflictividad, tanto en las aulas como en ambientes laborales".

30. "Los extranjeros no conocen las normas, son incívicos".

a) b) c) d) e)

31. "Las personas venidas de fuera de España son un elemento positivo en el crecimiento económico".

32. "Los inmigrantes abusan de los servicios sanitarios y llegan a colapsarlos".

33. "Podemos aprender mucho de los inmigrantes".

a) b) c) d) e)

34. "Hay que dar facilidades a los extranjeros para crear grupos con los que defender sus derechos".

a) b) c) d) e)

a) b) c) d) e)

35. “Debería haber zonas de viviendas donde los inmigrantes se relacionen entre ellos". a) b) c) d) e)

36. "Prevendría a un amigo si se quisiera casar con alguien de otra cultura".

a) b) c) d) e)

37. "Los inmigrantes no quieren integrarse y ellos mismos crean guetos".

a) b) c) d) e) 
38. “No tendría problema en tener una pareja de otra cultura o procedencia".

a) b) c) d) e)

39. "Los alumnos inmigrantes reducen el nivel educativo de los no inmigrantes". $\quad$ a) $\quad$ b) c) d) e)

40. "Los alumnos de otras culturas benefician una mejor educación en valores".

a) b) c) d) e)

41. "Los extranjeros tienen que adaptarse y adoptar nuestra cultura, dejando la suya de lado".

\section{BLOQUE 4. LA ENSEÑANZA DE LA HISTORIA SEGÚN LOS ALUMNOS DE GRADO EN PRIMARIA}

Imagine que ya es maestro y ha de plantear sus clases de ciencias sociales.

42. En cuanto a contenidos a incluir en sus clases, indique los principales hechos, acontecimientos, personajes y/o procesos históricos que -en su opinión- debe aprender el alumnado de primaria (intente ser breve):

Para las siguientes cuestiones, indique su opinión siendo a) Ninguno, b) Bajo, c) Moderado, d) Alto y e) Total:
43. ¿Cómo calificaría su interés por la historia?
b) c)
d) e)

a)

44. ¿Qué importancia tiene para usted la historia en el currículum de primaria?

b) c)

d) e)

45. Ordene los siguientes periodos históricos según su interés (sin repetir puntuación), siendo 1 el que menos le interesa y 5 el que más:
a) Prehistoria
b) Historia antigua
c) Historia medieval
d) Historia moderna
e) Historia contemporánea

46. Ordene las siguientes temáticas históricas según su interés (sin repetir puntuación), siendo 1 la que menos le interesa y 5 la que más:
a) Historia política e institucional
b) Historia social, historia de la familia y la vida cotidiana
c) Historia económica
d) Historia de la cultura
e) Historia del arte

47. Piense en una buena clase de historia. ¿Qué elementos (humanos, materiales, metodológicos,...) harían que fuese interesante para usted?

48. Indique la metodología principal que se utilizó en las clases de historia que recibió:

49. Explique brevemente cuál es la metodología que entiende más apropiada para la enseñanza de la historia en Educación Primaria, y que cree que debería introducir en sus clases: 


\section{BLOQUE 5. LA INTERCULTURALIDAD EN EL GRADO DE EDUCACIÓN PRIMARIA}

A continuación se presenta una serie de afirmaciones sobre el plan de estudios del Grado en Educación Primaria (sin entrar en los contenidos de las distintas asignaturas) así como sobre la formación que usted considera que deberían adquirir los futuros maestros para poder llevar a cabo, con garantías, la enseñanza de los valores y competencias cívicas y ciudadanas que las sociedades democráticas del siglo XXI han de afrontar, inmersas en pleno proceso de globalización.

Marque la respuesta, en cada fila, que mejor se ajuste a su opinión, siendo a) Totalmente en desacuerdo, b) Parcialmente en desacuerdo, c) No tengo una opinión formada al respecto, d) Parcialmente de acuerdo y e) Totalmente de acuerdo.

50. "Ya que el alumnado es mayoritariamente homogéneo, abordar la interculturalidad en la formación del profesorado es innecesario".

$\begin{array}{llll}\text { a) } & \text { b) } & \text { c) } & \text { d) }\end{array}$

51. "Es suficiente la existencia de charlas y seminarios, e innecesario que haya contenidos específicos en la carrera sobre estos temas".

a)

b)

c)

d)

e)

52. "Son necesarias varias asignaturas dentro de la titulación relacionadas con la interculturalidad para formar adecuadamente al profesorado".

a)

b)

c)

d)

e)

53. "El plan de estudios del grado incluye asignaturas comunes y contenidos suficientes para que todos los graduados, hagan la mención que hagan, sean capaces de llevar a cabo esa enseñanza en valores y competencias cívicas, democráticas e interculturales".

a)

b)

c)

d)

e)

54. "Los maestros y maestras deberían estudiar más contenidos de las asignaturas específicas y no detenerse en aspectos transversales como los valores y la identidad, ya que eso es algo que los alumnos y alumnas deberían aprender en casa".

a)

b)

c)

d)

e)

55. "Es totalmente posible formar futuros maestros que puedan enseñar la perspectiva del otro aunque el contexto educativo sea producto de las propias concepciones y valores".
a)
b)
c) d)
e)

Las siguientes afirmaciones están referidas a su experiencia dentro del Grado en Educación Primaria hasta el momento.

Marque la respuesta, en cada fila, que mejor se ajuste a su opinión, siendo a) Totalmente en desacuerdo, b) Parcialmente en desacuerdo, c) No tengo una opinión formada al respecto, d) Parcialmente de acuerdo y e) Totalmente de acuerdo.

56. "He recibido formación suficiente para hacer frente a una educación cargada de valores cívicos, democráticos e identitarios en las asignaturas comunes del Grado". a) b) c) d) e)

57. "Independientemente de los contenidos estudiados, me siento incapaz de hacer frente a un aula multicultural en mi futuro docente próximo".

a)

b)

c)

d)

e)

58. "Las asignaturas comunes del grado han mejorado mi visión hacia otras culturas".
a)
b)
c)
d) e)

59. "Las asignaturas comunes del grado han mejorado mi visión hacia la necesidad de una educación intercultural".

$\begin{array}{llll}\text { a) } & \text { b) } & \text { c) } & \text { d) }\end{array}$

60. "La mención prepara para una educación intercultural que atienda a la necesidad de formar ciudadanos preparados para una sociedad multicultural democrática, en la que imperen los valores de respeto y solidaridad".

a) b)

b) c)

d)

e)

61. "Hay contenidos en la mención sobre educación intercultural que no se tratan en las asignaturas comunes del grado que deberían ser comunes para todos aquellos que quieran dedicarse a la labor docente".
a)
b)
c)
d)
e)

62. "La mención debe incluir otros contenidos relacionados con la educación intercultural que ayuden a abordar las necesidades de nuestra sociedad y que no están incluidos”. a)

b)

c)

d)

e)

MUCHAS GRACIAS POR SU COLABORACIÓN 